1982 - at Winlow School yard on se21-130-W1.- Ronald Stevenson, Box 386, Gainsborough, Saskatchewan. SOC OZO

\section{THE WOODCHUCK IN SASKATCHEWAN}

This map gives the general distribution of the Woodchuck in Saskatchewan as derived from the map in The mammals of Canada [Banfield, A.W.F. 1974. Univ. of Toronto Press]. The sightings reported in the two notes appearing above, and the previous Blue Jay article mentioned, are denoted by black squares. There is a photograph of a Woodchuck in the Blue Jay files taken by Fred Lahrman at Craven northwest of Regina.

The Woodchuck was originally an in habitant of the forest edge and glades. In eastern North America it multiplied it areas where the habitat was modified by man into fields, pastures and fence rows Is it now expanding its range into the agricultural land within the prairies?

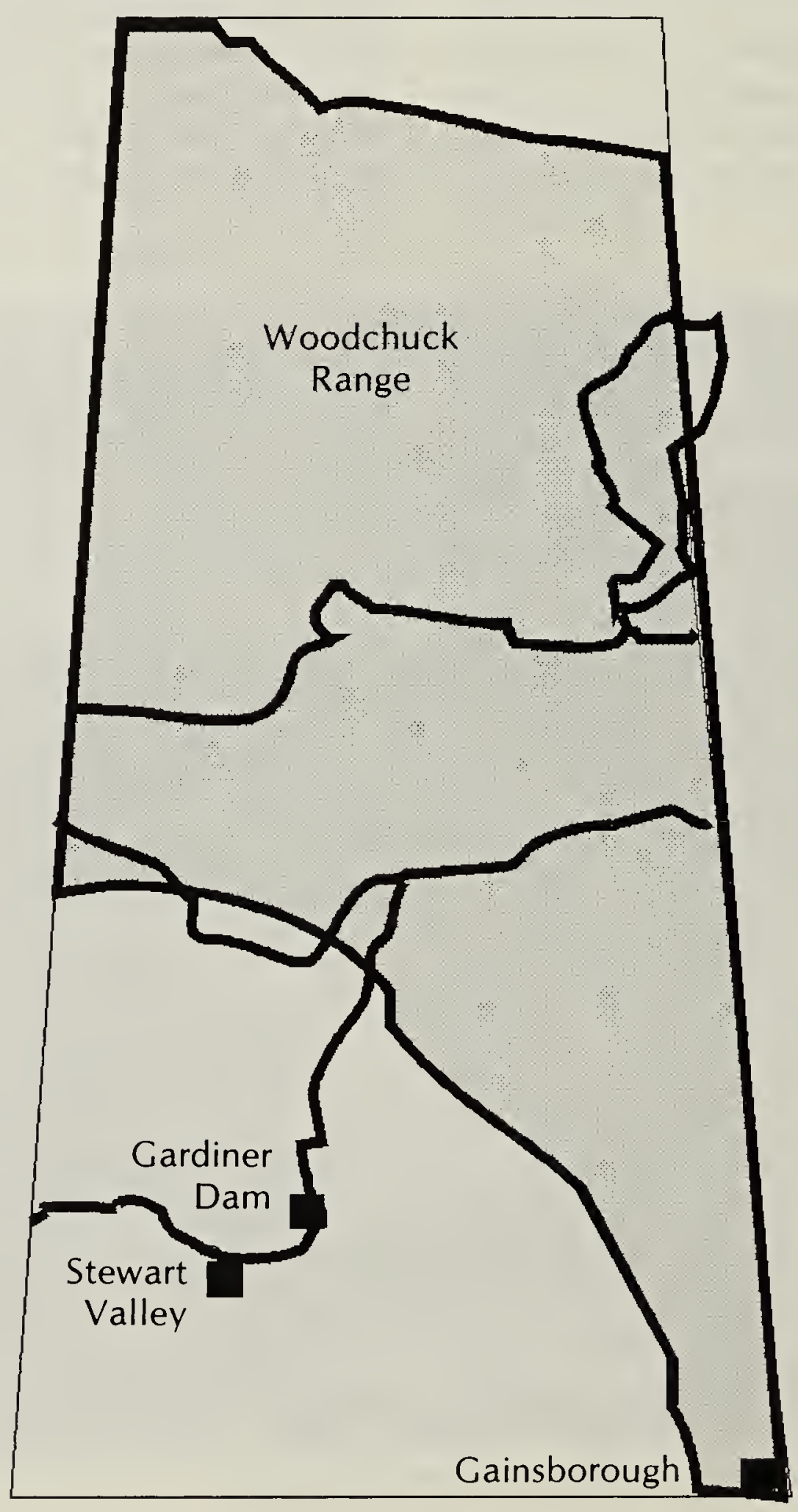

